\title{
An Economic Analysis of Trade-Secret Protection in Buyer-Seller Relationships
}

\author{
Stefan Bechtold \\ ETH Zurich \\ Felix Höffler* \\ University of Cologne
}

The economic analysis of trade-secret protection has traditionally focused on the interests of companies to conceal information from competitors in order to gain a competitive advantage through trade-secret law. This has neglected cases in which the interest is not in concealing information from competitors but from trading partners. We investigate trade-secret protection in such cases. Frequently, asymmetric information will lead to inefficient trade; at the same time, protecting private information might create incentives for socially desirable investments. We model this trade-off in a simple buyer-seller model and find that the optimal fine for violations of trade secrets is positive. In general, however, the welfare effects of increasing a fine are ambiguous. We discuss conditioning the legal protection on a minimum investment by the informed party to conceal the information and argue that this helps to apply trade-secret protection only when it increases welfare. This rationalizes important features of current legal practice. (JEL K2, D82)

\section{Introduction}

Confidentiality of information is often legally protected by trade-secret laws. A large body of literature exists that analyzes trade-secret protection and typically defines a trade secret as follows:

A trade secret is an item of information... that has commercial value and that the firm possessing the information wants to conceal from its competitors in order to prevent them from duplicating it. (Friedman et al. 1991: 61)

\footnotetext{
${ }^{*}$ Institute of Energy Economics, University of Cologne, and Max Planck Institute for Research on Collective Goods, Bonn, Germany. Email: hoeffler@wiso.uni-koeln.de.

We would like to thank Francine Lafontaine (the editor) and two anonymous referees for excellent comments. We are also grateful to Dan Burk, Christoph Engel, Mark Hahmeier, Martin Hellwig, Ben Hermalin, Jos Jansen, Peter-J. Jost, Alexander Morell, Urs Schweizer, Alexander Stremitzer, and Gerhard Wagner for helpful discussions. The usual disclaimer applies. Large parts of the work on the article were done while Stefan Bechtold and Felix Höffler were at the Max Planck Institute for Research on Collective Goods in Bonn, Germany. Felix Höffler gratefully acknowledges financial support from Deutsche Forschungsgemeinschaft through SFB-TR 15.
}

The Journal of Law, Economics, \& Organization, Vol. 27, No. 1, doi:10.1093/jleo/ewp020

Advance Access publication August 21, 2009

(C) The Author 2009. Published by Oxford University Press on behalf of Yale University.

All rights reserved. For Permissions, please email: journals.permissions@oxfordjournals.org 
Keeping such information secret seems warranted since-similar to patent protection-it creates incentives to invest in the generation of such valuable information in the first place (see, e.g., Kitch 1980; Friedman et al. 1991; Bone 1998).

Although these aspects are very important, such analysis neglects that confidentiality is desired not only in "horizontal" relationships between competitors but also "vertically" between trading partners. For instance, a buyer usually does not want the seller to know her exact valuation of the product since this can worsen her bargaining position. Although it is obvious that concealing such information is often valuable to the buyer, it is less clear whether such concealment is also socially beneficial.

An example of such a vertical case recently arose in the German energy industry. One of the key issues in the production of electric power is uninterrupted power supply. Power plants usually commit at least a day ahead to deliver a certain amount of electricity into the power grid. If the energy production at the power plant breaks down, the plant operator has to buy energy on a short-term basis in order to fulfill his commitment. Although, in such a situation, the potential seller would like to know how urgently the buyer needs additional power (as this would influence the price the seller would charge), the buyer is interested in keeping the breakdown of her plant secret.

Although power producers have traditionally been able to keep the production levels of their power plants secret, in recent years several companies have interfered with these attempts. In various countries, service companies provide real-time information on the energy production of power plants to potential electricity sellers and traders. These companies install measuring equipment under power supply lines leading out of power plants. By measuring the electromagnetic field emitted by the transmission lines, the equipment allows the service company to measure the electricity supplied by the power plant into the grid. ${ }^{1}$ Electricity traders can buy this information (almost) in real time. Since this reveals the power plant's ability to sell electricity—or, in case of outages, their need to procure additional electricity_power plant operators filed lawsuits against service companies that offer this information, arguing that the information is protected as a trade secret. As these service companies do not only operate in Germany but all over Europe and North America, similar cases may arise in other jurisdictions.

This raises the question to what extent a buyer should be able to keep information about her own valuation of a potential deal with a seller confidential or whether such information should always be divulged to the potential seller. Applying trade-secret law in such cases protects the asymmetry of information. This is irritating from an efficiency point since it is well understood that asymmetric information can lead to inefficiencies in buyer-seller relationships. Asymmetric information creates information rents, thereby giving rise to

1. In the United States, for example, Genscape, Inc., has been granted four patents on related measuring technologies (see, e.g., Genscape, Inc. 2004, 2006). Similar patents exist for measuring fluid flows in gas and oil pipelines (see, e.g., Genscape, Inc. 2007). 
the well-known trade-off between rents and efficiency. The uninformed party might rather abstain from trading than have to pay high information rents; thus, in the presence of asymmetric information, inefficient trade results. Myerson and Satterthwaite (1983) have shown that, under rather general conditions, no mechanism exists which guarantees efficient trade under asymmetric information, which is incentive compatible and individually rational, and exhibits a balanced budget.

However, information rents can also be socially beneficial if they result from investments by the informed party. If, in the absence of secrecy, the informed party were deprived of all rents, it would have no incentive to undertake efficient investments in the first place. This resembles the patent-like efficiency argument in "horizontal" trade-secret cases.

We investigate this trade-off between "efficient trade" (adverse selection) and "investment incentives" (moral hazard) in a simple model. A buyer and a seller trade one unit of an indivisible good. The buyer has an outside option, but its value is her private information. The seller makes a take-it-or-leave-it offer to trade the good. Before that, the buyer might undertake a nonverifiable relation-specific investment, increasing her valuation of the good, but leaving the outside option unaltered. We also allow for ex ante revealing investments of the uninformed party (the seller). It increases the likelihood of the information being revealed to the seller, who, in case of revelation, can appropriate all ex post gains from trade. Trade-secret protection implies that the seller is fined in case he attempted to find out the buyer's information.

There are two main findings. First, having trade-secret protection is always beneficial, that is, there should always be a remedy for violation of trade secrets. The reason is that the uninformed party (the seller) has a socially excessive interest to invest in revealing the information. With symmetric information, the seller is able to appropriate all gains from trade, that is, can use perfect price discrimination. This leads to ex post efficient trade. However, the seller's incentive to make information symmetric is motivated not only by the additional social surplus but also by appropriating the buyer's information rent. Remedies for trade-secret violation work against this socially excessive rent-seeking motive. Furthermore, asymmetric information and its protection is socially beneficial since it protects the buyer's information rent which increases in the relation-specific investment. Thus, returns on the relation-specific investment are protected and thereby trade-secret laws safeguard investment incentives.

The second main finding refers to a robust rule for the application of tradesecret protection. The optimum size of the fine depends on which of the underlying efficiency problems is dominant: the fine should be large if the underinvestment problem in the relation-specific investment is large; the fine should be small if the danger of (ex post) inefficient trade is dominant. A "conditional trade-secret protection rule" helps to apply trade-secret protection only when it is beneficial. This rule is often found in trade-secret laws. It says that for trade-secret protection to be applicable, the informed party must have undertaken some minimum effort to conceal the information. 
We discuss such concealing efforts and find that they tend to be small if the adverse selection problem is large. In this case, there should be little tradesecret protection, and-indeed-with the conditional trade-secret protection rule the expected fine for the uninformed seller will be small, that is, he has a large incentive to reveal the buyer's type, which increases the likelihood of efficient trade. To understand why this is the case, consider a situation where most buyers have an attractive outside option. In this case many of them will anticipate that it is best for them to go for the outside option. Since investments are relation specific, they will not invest at all. Thus, they never have any information rent-and thus no incentive to engage in costly concealing of information. This, in turn, reduces the expected fine for the seller, increases his incentive to invest in revelation, and thereby reduces the danger of inefficient trade.

For the opposite case, assume that the outside option is unattractive but the relation-specific investment is very effective. In such a case, the seller will set a price which many types of buyers will accept (like a monopolist who faces a demand where the lowest willingness to pay is very high). Thus, there is no adverse selection problem. However, the moral hazard problem is severe, and therefore high expected fines are sensible. The conditional trade-secret protection rule works in this direction: many buyers receive an information rent in case of asymmetric information, therefore all of them invest in concealing. This increases the expected fine and discourages revealing efforts - as it should from a social welfare perspective.

A key driver of our results, namely that private incentives for information revelation can be excessive, goes back at least to Hirshleifer (1971), who introduced the notion of "foreknowledge" which is valuable to its holder only due to its distributive effect not to its efficiency effect. This is an important argument contrary to the view that protection of secrecy of information generally tends to be welfare decreasing since more symmetric information should usually increase the efficiency of the allocation (in particular for the case of private information in employer-employee relationships, see Stigler 1980; Posner 1981). This discussion was taken up by Levin (2001) who-similar to our findings - finds ambiguous welfare effects of information revelation in buyerseller relations.

Finally, an article closely related is Hermalin and Katz (2006). They are concerned with the problem of "privacy" in particular of information of consumers or employees. They think of private information as being, in principle, verifiable as an "indicator variable" and ask who should have the "property rights" to this indicator variable: the informed or the uninformed party? They also find that the effects are ambiguous. The informed party need not be worse off when giving the property rights to the uninformed party, and, in this case, welfare need not be higher. The major difference to our article is that Hermalin and Katz focus on a detailed analysis of the adverse selection problem, whereas we also look at a moral hazard problem with respect to relation-specific investments. Furthermore, we model trade-secret protection as a mechanism which influences the likelihood of symmetric information rather than comparing different property rights regimes. 
Our analysis is complementary to the existing literature on trade secrets mentioned in the beginning (Kitch 1980; Friedman et al. 1991; Bone 1998), though clearly distinct since we focus on asymmetric information in vertical trading relationships, whereas the existing literature is concerned primarily with horizontal cases.

Furthermore, our article is also related to the literature on disclosure duties in contract law, such as Kronman (1978), Shavell (1994), or Grosskopf and Medina (2008). This literature is concerned with investments which increase the probability of efficient trade, whereas in our model the investment increases the ex post surplus. More technically, in our setting, the "type" of an agent is known to the agent, whereas in the disclosure duties literature it usually is not, for example, a contractor does not know the cost of the project (i.e., his own type) but might find it out when undertaking some information investment. In our model, the buyer always knows whether she has a strong or weak position vis-a-vis the seller. The investment always increases the value of the trade, given that trade occurs.

The remainder of the article is organized as follows. Section 2 discusses the legal framework we are evaluating. Section 3 introduces the basic intuition why trade-secret protection might be welfare reducing. Section 4 sets up the model, which is analyzed in Section 5. Section 6 discusses private damages and conditional trade-secret protection as institutions to implement trade-secret protection. Section 7 analyzes the optimal size of a fine punishing trade-secret violation. Section 8 briefly discusses applications in and beyond trade-secret laws. Section 9 concludes.

\section{Legal Framework}

Information about the buyer's valuation of a potential secret may, under certain circumstances, be protected as a trade secret. Although, in the United States, trade-secret protection is a matter of state law, the general rules are very similar across all states. Current state-level trade-secret protection is strongly influenced by the Third Restatement on Unfair Competition ${ }^{2}$ and the Uniform Trade Secrets Act, ${ }^{3}$ which codify traditional common law rules and which most states used as a point of reference when creating their trade-secret statutes.

In general, in order to qualify as a trade secret, information must confer an economic advantage when kept secret, it must be secret in fact, and it must be protected from disclosure by reasonable secrecy safeguards. Such safeguards may include confidentiality agreements, constructing fences or walls to block public view, using passwords, and restricting employee access to sensitive areas (see Uniform Trade Secrets Act §1(4); Bone 1998: 248-9; Milgrim 2008: $\S 1.01)$. Trade-secret protection is violated if the information is acquired, used,

2. Restatement (Third) of Unfair Competition $\S \S 39-45$ (1995), superseding the Restatement (First) of Torts $\S \S 757-759$ (1939).

3. Uniform Trade Secrets Act, 14 U.L.A. 433 (1985). 
or disclosed in breach of confidence, by violating an independent legal norm (such as laws against trespass, fraud, or theft) or by other improper means. ${ }^{4}$

Under the German Act Against Unfair Competition, in order to qualify as a trade-secret, information must be related to a firm, it must be known only to a limited number of people, the firm must have a legitimate interest in the secrecy, and it must be obvious that the firm wants to keep the information secret (see Hefermehl et al. 2008, $\S 17$ UWG note 4). Trade-secret protection is violated if the information is acquired, used, or disclosed without authorization, either by technical means or by creating or taking away a fixed copy of the information (see Section 17 of the German Act Against Unfair Competition).

Although the details of trade-secret protection differ across jurisdictions, the general requirements and limitations are very similar. In many jurisdictions, information can only be protected as a trade secret if the owner of the secret takes reasonable precautions to prevent disclosure. ${ }^{5}$ Without such precautions, there is no indication that the owner has a real interest in keeping the information secret. However, the law does not require such precautions to be perfect. In particular, it does not require the owner to guard against unanticipated, undetectable, or unpreventable methods of espionage that are very costly or even impossible to prevent. ${ }^{6}$ As a result a party can seek trade-secret protection only if it has shown some effort to conceal the information. At the same time, trade-secret protection puts a limit on the amount of required effort.

\section{Trade-offs of Trade-Secret Protection}

To formalize the trade-offs of trade-secret protection as a means to protect the secrecy of information, we discuss a simple buyer-seller relationship. Consider a buyer (she) and a seller (he) who can trade one unit of an indivisible good. Production costs for the seller are normalized to zero. The buyer's valuation of the good is $b>0$. The buyer has an alternative sourcing option at cost $c$, $b>c>0$. We assume that $c$ reflects the actual production cost of the good in the outside option (e.g., $c$ might be the cost at which the buyer could produce the good herself). The value $c$ is drawn from a smooth distribution $F$ with compact support on $[\underline{c}, \bar{c}]$, and its realization is private information to the buyer. The seller has all bargaining power, that is, he posts a take-it-or-leave-it offer by demanding a price $p$. The seller's payoff equals zero if no trade happens, otherwise it equals $p$. For the buyer, the payoff when trading with the seller is $b-p$, and $b-c$ otherwise. Therefore, trade will only happen if $p \leqslant c$.

The solution to this bilateral trading under asymmetric information is very similar to a standard monopoly problem. The probability that trade at price $p$

4. What constitutes other "improper means" is subject to considerable debate; see only E.I. duPont deNemours \& Company, Inc. v. Christopher, 431 F.2d 1012, 1016 (5th Cir. 1970).

5. For US trade-secret law, see Milgrim (2008), §1.03. For German trade-secret law, see Hefermehl et al. (2008), §17 UWG note 10.

6. E.I. duPont deNemours \& Company, Inc. v. Christopher, 431 F.2d 1012, 1016 (5th Cir. 1970). 


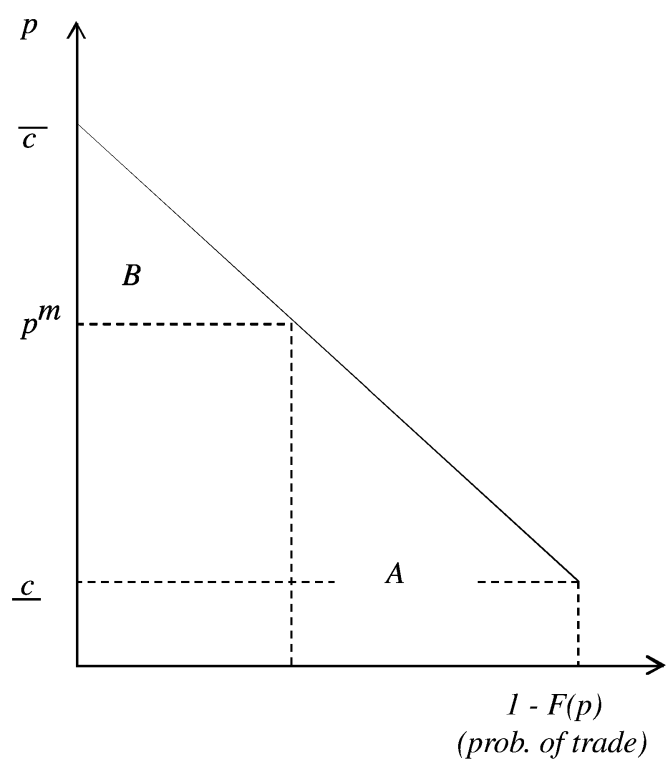

Figure 1. Optimum Pricing without Relation-Specific Investments.

occurs equals $1-F(p)$; thus, we can interpret $1-F(p)$ as a demand function. Therefore, the seller maximizes expected profits by maximizing

$\pi_{\mathrm{S}}=p(1-F(p)) \rightarrow \max _{p}$

If - what we want to assume in the following - the density function $f(p)$ is log-concave and thereby $1-F(p)$ is also log-concave, this problem has a unique solution (see Bagnoli and Bergstrom 2005, and the references therein), which we call $p^{m}$. The seller sets a monopoly price such that, for all realizations of $c<p^{m}$, inefficient trade occurs, whereas for all higher values of $c$, $c \geqslant p^{m}$, efficient trade takes place, and the buyer receives an information rent. Figure 1 shows the similarity of the problem to the standard monopoly problem, where the area $A$ reflects the deadweight loss from monopoly and the area $B$ the information rent (or consumer surplus).

With symmetric information, the seller would be able to set the price identical to $c$, implying efficient trade and no information rent. This welfare improvement from symmetric information is similar to the welfare improvement gained from perfect price discrimination in the standard monopoly problem. Helping to create symmetric information, for example, by abolishing tradesecret protection, therefore has the potential to increase efficiency.

However, this simple setup already suggests potentially beneficial effects of trade-secret protection. If buyers and sellers could engage in efforts to conceal or reveal the information, they would have a strict incentive to do so. The buyer would invest up to $B$ to protect the information. In the current framework, this is clearly socially wasteful. However, the seller's effort to reveal will also 
be socially excessive. The maximum the seller could gain from revealing the buyer's type is not only $A$ but also $A+B$.

Trade-secret protection, or, more precisely, punishments for its violation, might prevent the seller from engaging in (excessive) revealing effort. Therefore, trade-secret protection might be beneficial by reducing wasteful rentseeking activities.

Another argument in favor of trade-secret protection refers to the information rent $B$ : assume the buyer could engage in activities that increase her valuation for the good. If this increases her information rent, she will have an incentive to engage in such investment. However, if, with symmetric information, the buyer would be able to appropriate all consumer surplus, symmetric information removes investment incentives. To make these arguments more precise, we need a more complete model.

\section{Model}

We maintain the basic assumptions of Section 3 but add explicitly rent-seeking activities of the seller (we later discuss the effects of similar activities by the buyer), as well as investment of the buyer in the valuation of the good. We also specify how trade-secret protection works in this context.

In $t=0$, the buyer's type is determined. The realization of $c$ is private information. In $t=1$, the seller can engage in revealing effort $\gamma_{\mathrm{S}}$, causing costs of $\phi\left(\gamma_{S}\right)$ to the seller. To ensure interior solutions, we assume $\phi^{\prime}(0)=0, \phi^{\prime}>0$ for $\gamma_{S}>0, \phi^{\prime \prime}>0$, and $\lim _{\gamma_{S} \rightarrow \infty} \phi^{\prime}\left(\gamma_{S}\right)=\infty$. The investment cannot be observed by the buyer.

In $t=2$, the buyer can make a relation-specific investment $e$ to increase the value from trading with the seller. Thus, the valuation is now $b(e)$, with $b^{\prime}>0, b^{\prime \prime}<0, \lim _{e \rightarrow 0} b^{\prime}=\infty$, and $\lim _{e \rightarrow \infty} b^{\prime}=0$. The benefit from choosing the outside option is not affected by this investment: it always equals $b(0)$. The investment $e$ is nonobservable and nonverifiable. Therefore, with symmetric information, the holdup problem would arise since the seller would demand the total ex post surplus equal to $b(e)-[b(0)-c]$; anticipating this, the buyer would not invest at all, $e=0$.

After the choice of the investment, nature determines in $t=3$ whether the private information of the buyer, that is, her type $c$ and her investment level $e$, is revealed to the seller or not. Revelation happens with probability $\alpha\left(\gamma_{S}\right)>0$ with $\alpha^{\prime}>0$. The probability of symmetric information is always positive but increases the more the uninformed seller has invested to find out the buyer's type. Therefore, private information could always be revealed to the seller even if the seller had not undertaken any effort to reveal it. In many applications, it seems plausible that the information could become public just by chance (e.g., it could be published in a newspaper).

In $t=4$, the seller makes a take-it-or-leave-it offer $p$ to the buyer. In $t=5$, the seller might be punished for the violation of trade-secret protection. With probability $\beta<1$, the seller has to pay a fine $D$, where we assume $\beta(0)=$ $0, \beta^{\prime}>0$, and $\lim _{\gamma_{S} \rightarrow 0} \beta^{\prime}=0$. The harder he tried to find out, that is, the higher 


\begin{tabular}{|c|c|c|c|c|c|}
\hline$\stackrel{0}{4}$ & 1 & 2 & 3 & 4 & 5 \\
\hline $\begin{array}{l}\text { type of buyer } \\
\text { drawn } \\
c \in[\underline{c}, \bar{c}]\end{array}$ & $\begin{array}{l}\text { seller chooses } \\
\text { revealing effort } \\
\gamma_{S}\end{array}$ & $\begin{array}{l}\text { buyer chooses } \\
\text { relation- } \\
\text { specific } \\
\text { investment } \\
e\end{array}$ & $\begin{array}{c}\text { nature reveals } \\
c \text { and } e \text { with } \\
\text { probability } \\
\alpha\left(\gamma_{S}\right)\end{array}$ & $\begin{array}{c}\text { seller makes a } \\
\text { take-it-or- } \\
\text { leave-it offer } p \text {, } \\
\text { buyer buys or } \\
\text { uses outside } \\
\text { option }\end{array}$ & $\begin{array}{c}\text { with } \\
\text { probability } \\
\beta, \text { the seller } \\
\text { pays a fine } \\
D\end{array}$ \\
\hline
\end{tabular}

Figure 2. Timing.

$\gamma_{S}$, the higher the probability of getting caught. If he did not try to reveal, he will not be fined, that is, $\beta(0)=0$. That punishments are conditional on attempts to reveal the private information is in line with the currently used trade-secret law, as pointed out in Section 2. The same is true for assuming $\beta(0)=0$ : without a deed, there is no punishment. ${ }^{7}$ The fine $D$ reduces the seller's payoff but does not (directly) affect the buyer's payoff. This would be the case, for example, for a prison sentence or a fine payable to the public budget (trade-secret laws allow for prison sentences). ${ }^{8}$

Note that our assumptions imply that trade-secret protection can never prevent the seller from using the information once it is revealed to him. This captures the idea that it is impossible to credibly commit to forget something. However, trade-secret protection can reduce the seller's effort to reveal the information by the threat of punishment in case of detection. Figure 2 summarizes the timing of the events.

The overall payoffs of the buyer and the seller are given by

$\pi_{\mathrm{B}}= \begin{cases}b(e)-p-e & \text { if trading with the seller } \\ b(0)-c-e & \text { if using the outside option }\end{cases}$

$\pi_{\mathrm{S}}= \begin{cases}p-\phi\left(\gamma_{\mathrm{S}}\right)-\beta D & \text { if trading with the buyer } \\ -\phi\left(\gamma_{\mathrm{S}}\right)-\beta D & \text { if no trade occurs. }\end{cases}$

We look for a perfect Bayesian equilibrium of this game.

\section{Equilibrium Analysis}

Since neither $\gamma_{S}$ nor $e$ is ever observed by the other party before $t=3$, the strategic variables of the buyer and the seller are to be determined as if they were chosen simultaneously. In equilibrium, buyers know the price $p^{m}$ the seller will charge. If they exert positive effort $e>0$ to increase the valuation of

7. An alternative assumption could be to condition the punishment on the actual use of the information. We will later take up this point when discussing "private damages."

8. See, for example, $\S 499 \mathrm{c}$ of the California Penal Code and Section 17 of the German Act Against Unfair Competition which allows for prison sentences of up to 5 years for severe tradesecret violations. 
inside trade, this will be determined by

$$
\begin{aligned}
\max _{e}(1-\alpha)\left[b(e)-p^{m}\right]-e & \rightarrow \\
b^{\prime}\left(e^{*}\right) & =\frac{1}{1-\alpha} .
\end{aligned}
$$

This reflects the underinvestment problem due to the holdup in case of symmetric information (first best effort requires $b^{\prime}\left(e^{\mathrm{FB}}\right)=1$ ).

If the buyer's type is revealed in $t=3$, which happens with probability $\alpha$, the seller executes perfect price discrimination and sets a price equal to the ex post surplus in excess of the outside option, which is equal to

$p_{\mathrm{sym}}^{m}=b(e)-(b(0)-c)$.

Alternatively, the buyer's type is not revealed in $t=3$. Then the buyer receives an information rent and she can try to increase the information rent by investing in $e$. In this sense, asymmetric information protects investment incentives.

However, not all types may get an information rent. Buyers can anticipate the price $p^{m}$ the seller will demand. Buyers with a very attractive outside option (a low $c$ ) anticipate that, with asymmetric information, they will still prefer the outside option, even if they invested in increasing the valuation from inside trading. These low $c$ types therefore never receive a return on investing (not with asymmetric information and obviously not with symmetric information) and therefore abstain from investing. An indifferent type $\widehat{c}$ exists who anticipates that-if investing optimally (i.e., taking into account the fact that, with probability $\alpha$, she will lose the returns on the relation-specific investment)she will be indifferent between trading with the seller and the outside option:

$b(0)-\widehat{c}=p^{m}-b\left(e^{*}\right) \rightarrow \widehat{c}=p^{m}-\left(b\left(e^{*}\right)-b(0)\right)$.

The seller, in turn, anticipates the optimal investment decision and demands the monopoly price $p^{m}$ in case that information is not revealed. Figure 3 depicts this situation.

Note that, in particular, if investments are very effective, that is, $b\left(e^{*}\right)-b(0)$ is large, the seller might find it optimal to trade with all types, that is, $\widehat{c}=\underline{c}$ and $p^{m}=\underline{c}+b\left(e^{*}\right)-b(0)$. In this case, efficient trade always occurs (the outside option is never used); unfortunately, the holdup problem is not solved: since $\alpha>0$, underinvestment still happens.

The seller's ex ante profit is given by

$$
\begin{aligned}
\pi_{\mathrm{S}}= & \alpha\left(\gamma_{\mathrm{S}}\right)\left[\int_{\widehat{c}}^{\bar{c}}\left[b\left(e^{*}\right)-(b(0)-c)\right] \mathrm{d} F(c)+\int_{\underline{c}}^{\widehat{c}} c \mathrm{~d} F(c)\right] \\
& +\left(1-\alpha\left(\gamma_{\mathrm{S}}\right)\right) \int_{\widehat{c}}^{\bar{c}} p^{m} \mathrm{~d} F(c)-\phi\left(\gamma_{\mathrm{S}}\right)-\beta\left(\gamma_{\mathrm{S}}\right) D .
\end{aligned}
$$

The term in the first line is the net profit in case of symmetric information, resulting from a pricing according to equation (3). The second line is the profit 


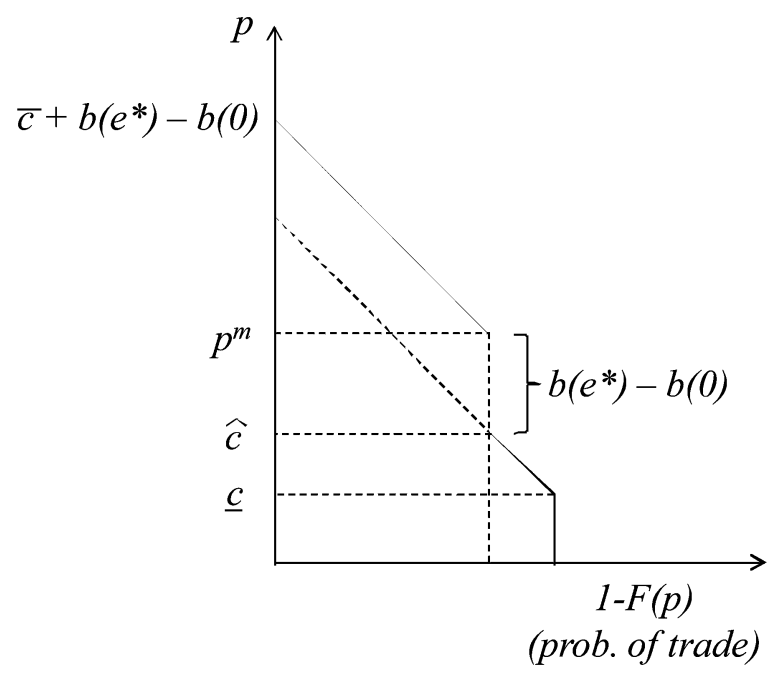

Figure 3. Relation-Specific Investment.

in case of asymmetric information minus cost for revealing investments and the potential fine. Only if the type of the buyer is above $\widehat{c}$, will the buyer accept the price $p^{m}$. Otherwise, no trade happens with the seller, and the seller's profit is zero for low $c$ types.

If information remains asymmetric, the seller chooses $p^{m}$ to maximize $\int_{\widehat{c}}^{\bar{c}} p^{m}$ $\mathrm{d} F(c)$, taking $\widehat{c}$ as given (a change in the equilibrium price $p^{m}$ will change $\widehat{c}$, but for deriving the Nash equilibrium price $p^{m}$ the strategy of the buyer, which includes the cutoff value $\widehat{c}$, is taken as given):

$$
\begin{aligned}
& \max _{p^{m}} p^{m}\left(1-F\left(p^{m}-\left(b\left(e^{*}\right)-b(0)\right)\right)\right), \\
p^{m}= & \frac{1-F\left(p^{m}-\left(b\left(e^{*}\right)-b(0)\right)\right)}{f\left(p^{m}-\left(b\left(e^{*}\right)-b(0)\right)\right)} .
\end{aligned}
$$

Due to the log-concavity of $f(c)$, this maximization has (like in Section 4) a unique solution.

The optimum choice of revealing investment $\gamma_{S}$ of the seller is given by differentiating equation (5) with respect to $\gamma_{S}$ :

$$
\frac{\partial \alpha}{\partial \gamma_{\mathrm{S}}}\left[\int_{\widehat{c}}^{\bar{c}} c \mathrm{~d} F(c)+\int_{\widehat{c}}^{\bar{c}} b\left(e^{*}\right)-(b(0)-c)-p^{m} \mathrm{~d} F(c)\right]=\frac{\partial \phi}{\partial \gamma_{\mathrm{S}}}+\frac{\partial \beta}{\partial \gamma_{\mathrm{S}}} .
$$

Increasing $\gamma_{S}$ increases the likelihood of symmetric information. The first term in the square brackets of equation (7) is the social benefit from perfect price discrimination. The second term reflects a socially excessive, rent-seeking motivation to invest in revealing the buyer's type in order to appropriate the information rent if trade also occurs also under asymmetric information. 
These discussions highlight three sources of welfare losses. First, like in Section 4 , there is an adverse selection problem since sometimes inefficient trade will occur. Formally, this is reflected in equation (4), which implies that $\widehat{c}$ can be larger than $\underline{c}$. Second, there is the moral hazard problem resulting from the holdup problem. Formally, this is reflected in equation (2), implying that $e^{*}$ is smaller than the first best effort level. Third, there is wasteful rent seeking by the uninformed party, formally reflected in equation (7).

Due to our assumptions on the cost functions $\phi$ and $b$ and on $\beta$, the conditions (2), (4), (6), and (7) determine a unique Bayesian Nash equilibrium of the game.

Proposition 1. There exists a unique Bayesian Nash equilibrium which simultaneously determines $e^{*}, \widehat{c}, p^{m}$, and $\gamma_{\mathrm{S}}$.

If the relation-specific investment $e^{*}$ increases, this increases the ex post surplus. Therefore, the seller's incentive to appropriate it by making information symmetric increases as well. As a result the best response function of the seller with respect to the revealing investment $\gamma_{\mathrm{S}}$ is strictly increasing in $e$. It is also intuitive that the optimum effort $e^{*}$ is decreasing in $\gamma_{\mathrm{S}}$ : the higher the $\gamma_{S}$, the higher the probability $\alpha$ that the buyer's type will be revealed and that the buyer will be subject to a holdup which expropriates all returns from her investment $e$.

What is important to note is how changes in $e$ affect the price $p^{m}$ and the cutoff buyer type $\widehat{c}$. An increase in $e$ increases the valuation $b(e)$ and thereby it will also increase the price set by the seller in case of asymmetric information, $p^{m}$, since the demand function he faces is shifted outwards. However, the price decreases by less than the shift in the demand function. As a consequence, the cutoff buyer type $\widehat{c}$ decreases. The difference between $b(e)$ and $p^{m}$ increases, and hence more buyer types find it attractive to invest and accept the seller's offer in case of asymmetric information. Note that this is like a "social double dividend" from an increase in $e$ : less severe underinvestment (a less severe moral hazard problem) and less inefficient trade (a reduced adverse selection problem). As a negative consequence, the wasteful revealing effort $\gamma_{S}$ will also increase.

\section{Optimum Fine $D$}

If a fine $D$ is introduced for trying to reveal the information of the buyer, this clearly discourages investing in revelation. In the $\left(e, \gamma_{\mathrm{S}}\right)$-space, the best response function of the seller is shifted inwards (see Figure 4). The equilibrium effort level $e$ will rise and the equilibrium revealing investment $\gamma_{\mathrm{S}}$ will go down. As a consequence, the valuation $b(e)$ as well as the price $p^{m}$ increase, whereas $\widehat{c}$ goes down.

Since, as pointed out in Section 5, in the absence of a fine, there are three sources of inefficiencies (too low $e$, too high $\widehat{c}$, and too high $\gamma_{\mathrm{S}}$ ), the introduction of a (small) fine is welfare increasing. 


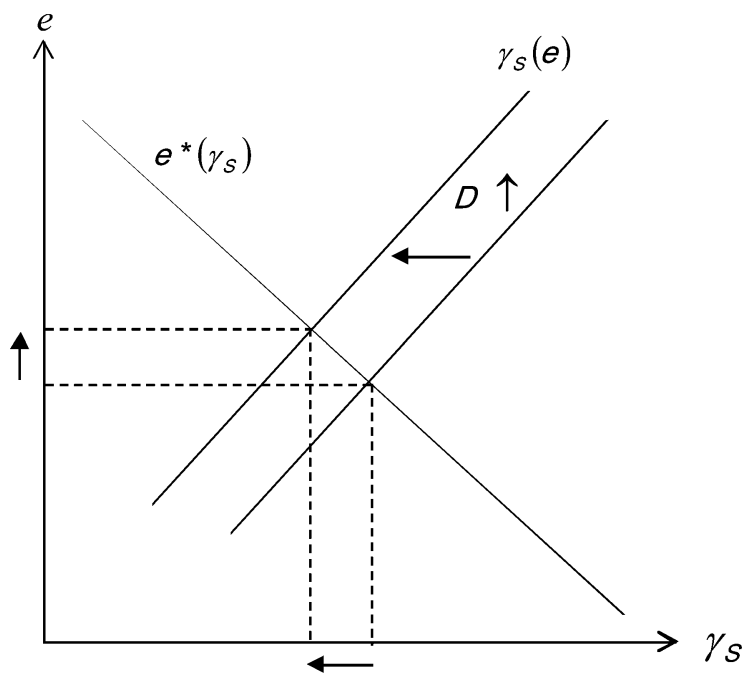

Figure 4. Increase in Fine $D$.

Proposition 2. The optimum fine is positive.

Corollary 1. The optimum fine increases the price $p^{m}$ compared to a situation without a fine.

The corollary is immediate from our discussion of the effect of $e$ on $p^{m}$. To see why the proposition is true, we can look at the expected total surplus:

$$
\begin{aligned}
\mathrm{TS}= & \left(1-\alpha\left(\gamma_{\mathrm{S}}\right)\right) \int_{\widehat{c}}^{\bar{c}}(c-\widehat{c}) \mathrm{d} F(c)+\int_{\underline{c}}^{\bar{c}}(b(0)-c) \mathrm{d} F(c)-\int_{\widehat{c}}^{\bar{c}} e^{*} \mathrm{~d} F(c) \\
& +\alpha\left(\gamma_{\mathrm{S}}\right)\left[\int_{\widehat{c}}^{\bar{c}}\left(b\left(e^{*}\right)-b(0)+c\right) \mathrm{d} F(c)+\int_{\underline{c}}^{\widehat{c}} c \mathrm{~d} F(c)\right] \\
& +\left(1-\alpha\left(\gamma_{\mathrm{S}}\right)\right) \int_{\widehat{c}}^{\bar{c}}\left(b\left(e^{*}\right)-b(0)+\widehat{c}\right) \mathrm{d} F(c)-\phi\left(\gamma_{\mathrm{S}}\right) .
\end{aligned}
$$

The first line is the buyer's expected profit. In case of asymmetric information, she receives an information rent if she has a bad outside option $(c>\hat{c})$ on top of her reservation utility $(b-c)$. Only if she turns out to have a bad outside option, will she invest $e^{*}$.

The second line is the seller's profit in case that information becomes symmetric: for buyers who have invested, he sets a price equal to the ex post surplus in excess of the outside option, and for the noninvesting types, the price just matches the price of the outside option $c$.

The third line is the seller's profit in case that information remains asymmetric minus the cost of the revealing investment $\gamma_{S}$ : the seller sets the price $p^{m}=b\left(e^{*}\right)-b(0)+\widehat{c}$, but only types with a bad outside option accept the offer. 
Thus, total welfare equals the sum of the expected buyer and seller profit in case of a fine $D=0$ (the fine is a pure transfer from the seller to the state and we assume that no welfare losses are attached to this transfer).

We are interested in the effect of introducing a fine, that is, we look at the derivative of TS with respect to $D$ at $D=0$. This is simplified by use of the envelope theorem: We need to look only at the direct effect of $D$ on equation (8), that is, the effect via a change in $\gamma_{S}$, and neglect the effect via a change in $e$ since $e$ is chosen to maximize the buyer's profit in equilibrium:

$\frac{\partial(8)}{\partial D}=-\frac{\partial \alpha}{\partial \gamma_{S}} \frac{\partial \gamma_{S}}{\partial D} \int_{\widehat{c}}^{\bar{c}}(c-\widehat{c}) \mathrm{d} F(c)>0$

Due to the envelope theorem, we can neglect the indirect effect of $D$ via $\gamma_{S}$ on the buyer's profit at $D=0$ since in equilibrium $\gamma_{S}$ and $p^{m}$ are chosen to maximize this profit:

$$
\begin{gathered}
\frac{\partial(9)}{\partial D}=\frac{\partial b}{\partial e^{*}} \frac{\partial e^{*}}{\partial D}(1-F(\widehat{c}))>0, \\
\frac{\partial(10)}{\partial D}=-(1-\alpha) \frac{\partial \widehat{c}}{\partial D}\left(f(\widehat{c}) p^{m}\right)>0 .
\end{gathered}
$$

The first positive welfare effect (equation 11) is the shift in rents from the seller to the buyer. This is welfare increasing at the margin since the loss in profit for the seller is offset by the reduction in wasteful revealing investment $\gamma_{S}$, thus we are left with the net welfare benefit for the buyer.

The second positive welfare effect (equation 12) stems from the reduction of the holdup problem. The fine reduces the likelihood of being held up, thus it increases the effort and the value $b(e)$ of all types with $c>\widehat{c}$.

The third positive welfare effect (13) is an indirect effect from the reduction of the holdup problem. As $D$ is introduced, $\widehat{c}$ decreases. This means that more buyers invest (marginally, the number is $f(\widehat{c})$ ). In the case of asymmetric information (i.e., with probability $(1-\alpha)$ ), all investing buyers will be willing to accept the seller's price $p^{m}$. Otherwise, they would have rejected the seller's offer and would have chosen the outside option. As a result the seller's profit increases exactly by $p^{m}$ in these cases.

Thus, the introduction of a (small) fine not only increases welfare but is also a Pareto improvement.

Corollary 2. The introduction of a small fine increases the seller's profit and the buyer's profit.

The buyers benefit from the fine only by an increase in their expected information rent. More precisely, by an increase in the probability that they will get the information rent. Although the fine leads to a reduction of the holdup problem, and thereby in equilibrium to a higher surplus from efficient trade, the buyers do not benefit from that. This is obvious in the case where information becomes symmetric. But even if information is asymmetric, since in equilibrium the seller knows the buyer's value $b\left(e^{*}\right)$ and adjusts the price 
(see equation (8)), the buyer does not benefit from the increase in the surplus for a given type $c>\widehat{c}$. Therefore, the only gain for the buyer results from the lower value of $\alpha$, implied by $D>0$, and thereby from the higher probability of obtaining an information rent.

\section{Discussion}

A small fine increases welfare. A large fine, however, might reduce welfare. That a small fine increases welfare is partly due to the effect that it reduces the excessive incentive for the seller to invest in revelation of the information. Incentives are excessive to the extent that they are motivated by rent seeking, but they can also be welfare increasing, as pointed out already in Section 3. Investments $\gamma_{\mathrm{S}}$ increase $\alpha$ and therefore reduce the danger that the inefficient outside option is used.

Compared to the first best, where all buyers trade with the seller and the first best effort $e^{\mathrm{FB}}$ is chosen, the welfare loss under asymmetric information equals

$$
\begin{aligned}
\mathrm{WL}= & (1-F(\widehat{c}))\left[b\left(e^{\mathrm{FB}}\right)-e^{\mathrm{FB}}-\left(b\left(e^{*}\right)-e^{*}\right)\right] \\
& +F(\widehat{c})\left[b\left(e^{\mathrm{FB}}\right)-e^{\mathrm{FB}}-b(0)\right]+(1-\alpha) \int_{\underline{c}}^{\widehat{c}} c \mathrm{~d} F(c)+\phi\left(\gamma_{\mathrm{S}}\right) .
\end{aligned}
$$

The first two terms reflect the moral hazard terms and the underinvestment problem. The third term is the welfare loss due to inefficient trade. The welfare loss varies with $D$ according to

$$
\begin{aligned}
& -\frac{\partial F(\widehat{c})}{\partial D}\left[b\left(e^{\mathrm{FB}}\right)-e^{\mathrm{FB}}-\left(b\left(e^{*}\right)-e^{*}\right)\right]-\frac{\partial\left(b\left(e^{*}\right)-e^{*}\right)}{\partial D}(1-F(\widehat{c})) \\
& +(1-\alpha) \frac{\partial \widehat{c}}{\partial D} \widehat{c} \mathrm{~d} F(c)+\frac{\partial \phi}{\partial D}-\frac{\partial \alpha}{\partial D} \int_{\underline{c}}^{\widehat{c}} c \mathrm{~d} F(c) .
\end{aligned}
$$

All of these terms are positive except for the last one, which reflects that an increase in $D$ has the undesirable property that asymmetric information becomes more likely and therefore the welfare loss from choosing the outside option increases.

A (large) fine will therefore be welfare decreasing if this last expression is large. This term will be large if (1) $\widehat{c}$ is high, which happens if $e$ is very ineffective and $b\left(e^{*}\right)-b(0)$ is small, (2) there are many buyers with a good outside option, and (3) generally, the support $[\underline{c}, \bar{c}]$ is large. The left graph in Figure 5 depicts such a situation, where $A$ is the potential welfare loss due to asymmetric information and $C$ indicates the welfare gain from avoiding moral hazard. ${ }^{9}$

Another extreme (the right graph in Figure 5) would be where the investment $e$ is very effective such that even under asymmetric information the seller

9. If $b\left(e^{*}\right)-b(0)$ is small, then probably also $b\left(e^{\mathrm{FB}}\right)-b\left(e^{*}\right)$ is small, although this is not necessarily the case. 
Dominant adverse selection problem

Dominant moral hazard problem
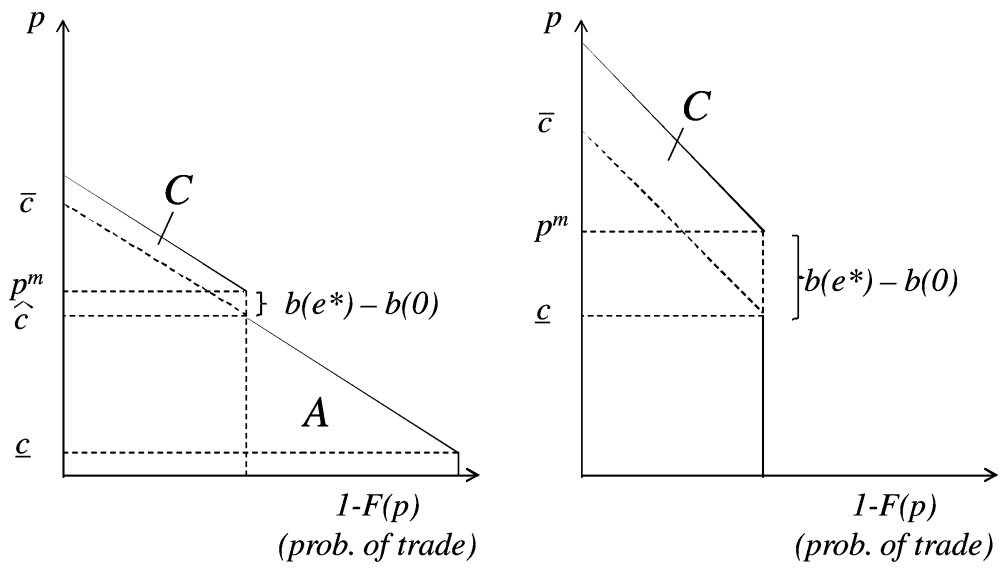

Figure 5. Efficiency Problems.

would like to trade with all types, that is, $\widehat{c}=\underline{c}$. This is similar to a monopolist who faces a demand function where serving even the lowest willingness to pay implies marginal revenues in excess of marginal cost. In such a case, there is no adverse selection problem. Without an adverse selection problem, the fine should be very high. First, in order to increase investment incentives $e$. Second, in order to deter rent-seeking activities $\gamma_{S}$.

To determine the optimal size of the fine $D$ therefore requires detailed information on the type distribution and the cost functions. It is reasonable to assume that legislators and courts lack such information. In the following, we will discuss welfare properties of simple, informationally undemanding rules that are used in legal practice.

\subsection{Private Damages}

So far we have assumed an exogenous remedy $D$ which did not affect the buyer's payoff directly. However, punishment for trade-secret violation frequently takes the form of private damages, ${ }^{10}$ that is, the level of punishment is endogenous and directly increases the buyer's payoff.

A key question is: What is the damage? In our model, the damage to the buyer is her lost information rent. Let us assume that a court could verify ex post the size of the lost information rent. For instance, it could compare the "usual" price (in case of no trade-secret violation) to the price charged in case of a violation. In this case, the expected punishment would no longer be $\beta\left(\gamma_{S}\right) D$

10. Along these lines, Section 3 of the Uniform Trade Secrets Act provides several ways to calculate damages: punitive damages, the calculation of the actual loss caused by misappropriation, the additional unjust enrichment caused by misappropriation, or the calculation of a reasonable royalty. 
but would equal

$\alpha \beta\left(\gamma_{\mathrm{S}}\right) \int_{\widehat{c}}^{\bar{c}} b\left(e^{*}\right)-b(0)+c-p^{m} \mathrm{~d} F(c)$.

If information becomes symmetric and litigation occurs, the seller has to pay damages to the buyer. The size of this payment is equal to the information rent which the buyer would have received if the information had been kept secret.

This scheme tends to have positive welfare effects since the size of the punishment varies with the information rent. If the relation-specific investment is very effective $\left(b\left(e^{*}\right)-b(0)\right.$ is very large $)$, then not only the gain from making information symmetric but also the punishment increases. Therefore, $\gamma_{S}$ tends to be small and therefore $\alpha$ will also be small, implying high investment incentives for the buyer, which is particularly beneficial if $b\left(e^{*}\right)-b(0)$ is large. In the opposite extreme, if the investment is not effective $\left(b\left(e^{*}\right)-b(0) \rightarrow 0\right)$, automatically, the expected fine is low.

\subsection{Conditional Trade-Secret Protection}

Private damages rely on the assumption that the size of the damage can be verified by courts. In "horizontal" cases of trade-secret violation, this might be relatively easy. Similar to a patent case, the court could try to calculate an equivalent to foregone licensing royalties to estimate the damage. In our "vertical" cases, calculating the information rent is much more difficult.

We now would like to discuss an alternative approach that does not need to rely on the - arguably unrealistic_assumption that private damages tailored to the size of the lost information rent are possible. We return to the assumption of an ex ante fixed fine $D$.

In most legal systems, trade-secret protection can only be sought-and therefore its violation can only be litigated-if the informed party has undertaken some effort to keep the information secret (see Section 2, n. 5). Imagine a variation of our model. In $t=0$, the seller chooses $\gamma_{\mathrm{S}}$ and the buyer chooses some effort $\gamma_{B} \cdot \gamma_{B}$ is a "concealing" investment which decreases the likelihood of the information being revealed to the seller, $\alpha\left(\gamma_{S}, \gamma_{B}\right)$, where $\partial \alpha / \partial \gamma_{B}<0$. The costs to the buyer are $\phi\left(\gamma_{B}\right)$. Since the concealing investment is chosen before the type of the buyer is determined, the choice of $\gamma_{\mathrm{B}}$ and therefore $\alpha$ and the realization of whether information remains asymmetric cannot reveal anything about the buyer's type. ${ }^{11}$ The buyer's decision problem when choosing $\gamma_{\mathrm{B}}$ in $t=0$ is then to maximize

$b-\int_{\underline{c}}^{\bar{c}} c \mathrm{~d} F(c)+(1-\alpha) \int_{\widehat{c}}^{\bar{c}}(c-\widehat{c}) \mathrm{d} F(c)-e^{*}(1-F(\widehat{c}))-\phi\left(\gamma_{\mathrm{B}}\right)$.

11. This timing also makes sense in the electricity example. An electricity company will formulate a long-term policy with respect to secrecy of information, whereas the question of additional electricity needed varies from day to day. 
An investment $\gamma_{\mathrm{B}}$ has a direct effect only on $\alpha .{ }^{12}$ Thus, the buyer will invest a lot if the information rent $\int_{\widehat{c}}^{\bar{c}}(c-\widehat{c}) \mathrm{d} F(c)$ is large. The information rent will be large if $\widehat{c}$ is small. This tends to be the case if the effort investment $e$ is very effective and $b\left(e^{*}\right)-b(0)$ is large since a high $e$ leads to a low $\widehat{c}$. Therefore, if the holdup problem is very severe, the buyer will have a large interest in asymmetric information and invest a lot in $\gamma_{\mathrm{B}}$.

A high $\gamma_{\mathrm{B}}$ is thus an indicator for a severe welfare problem stemming from moral hazard. In these cases, a (relatively large) fine should be applied. A low $\gamma_{\mathrm{B}}$ indicates the opposite: the buyer has little to gain from asymmetric information, for instance, because $e$ is very ineffective and therefore $\widehat{c}$ is relatively large. If $\widehat{c}$ is close to $\bar{c}$, then we have a severe adverse selection problem, and it tends to be welfare superior to have symmetric information. Thus, a rather low fine should be applied.

A "conditional trade-secret protection" rule is a rule which states that a fine should only be imposed if the buyer can show that she has undertaken some significant effort to conceal her information:

$D \begin{cases}>0 & \text { if } \gamma_{\mathrm{B}} \geqslant \varepsilon>0, \\ =0 & \text { otherwise. }\end{cases}$

Such a rule is easy for courts to apply and, as pointed out, a standard procedure in legal practice. Our analysis indicates that it can be viewed as an imperfect, ${ }^{13}$ though pragmatic mechanism that helps to apply trade-secret protection only in those cases in which it is more likely to be welfare improving.

\section{Application in and beyond Trade-Secret Law}

Conflicts involving asymmetric information in buyer-seller relationships, as analyzed in this article, can be found in trade-secret case law, both in Germany and in the United States. The German electricity case, which was described in Section 1, was settled before a district court in early 2006. It seems unlikely that a court would have found the service company installing the electromagnetic measuring devices to violate German trade-secret law. This is in line with

12. A full equilibrium analysis for the case with concealing investment is beyond the scope of this article. Obviously, $\gamma_{\mathrm{B}}$ will have an effect on the equilibrium level $\gamma_{\mathrm{S}}$ and therefore on $\widehat{c}, e^{*}$, and $p^{m}$. However, the buyer takes $\gamma_{\mathrm{S}}$ and $p^{m}$ as given (they are actually chosen simultaneously), and $\widehat{c}$ and $e^{*}$ are conditional on $\gamma_{\mathrm{S}}$ and $p^{m}$ and on the type realization $c$. Nothing of this can affect the incentives to invest in $\gamma_{\mathrm{B}}$ directly.

13. Our analysis highlights two imperfections. First, although the optimum fine might be small, it should never be exactly zero, even if there was little or no concealing effort. Second, if one looks at the left graph in Figure 5, one could imagine situations in which the welfare loss $A$ is small while the information rent $\int_{\widehat{c}}^{\bar{c}}(c-\widehat{c}) \mathrm{d} F(c)$ is large. Thus, in the absence of a fine $D$, there could be a huge, inefficient investment $\gamma_{S}$ which outweighs the welfare gain from avoiding the small welfare $\operatorname{loss} A$.

Finally, a fine $D$ could have the effect of increasing the incentive to invest in (wasteful) concealing efforts, $\gamma_{B}$. This happens if a decrease in $\gamma_{S}$ triggers a very strong increase in $\gamma_{B}$. Whether $\gamma_{S}$ and $\gamma_{B}$ are strategic substitutes or complements depends on the functional form of $\alpha\left(\gamma_{S}, \gamma_{B}\right)$, which determines whether a decrease in $\gamma_{\mathrm{S}}$ increases or decreases the marginal productivity of $\gamma_{\mathrm{B}}$. 
our model, which shows that trade-secret protection should only be granted if the informed party has made some effort to conceal its information, which was not the case in the electricity example. In the United States, whether tradesecret protection applies to information in buyer-seller relationships depends on the factual circumstances of the case. Often, costs and input factors cannot be protected as trade secrets either because they are well known throughout the industry ${ }^{14}$ or because the informed party took no measures to keep the information confidential. ${ }^{15}$ In general, whether information about a buyer's willingness to pay can be protected as a trade secret depends on whether the information in question is easily available by other means and whether the owner is able to and does in fact make attempts to keep the information secret.

The basic idea that the legal protection of asymmetric information about outside options has ambiguous welfare effects in some particular buyer-seller relationships applies to many other legal areas outside trade-secret law as well. First, US courts sometimes deny requests in buyer-seller relationships for disclosing information collected by the government. Such decisions concern the trade-secret exemption to the Freedom of Information Act, ${ }^{16}$ rulemaking procedures of the Federal Energy Regulatory Commission, ${ }^{17}$ and securities regulation. ${ }^{18}$ Second, although corporate law usually grants stockholders a broad right to inspect the corporation's books and records, the stockholder is neither allowed to use his right to inform a customer of the corporation nor allowed to use this information in contract negotiations with the corporation. ${ }^{19}$ Third, such cases can arise if a company engages in price discrimination and wants to prevent its various customer groups from finding out the different prices offered. ${ }^{20}$

This short survey demonstrates that the question of whether information asymmetries about outside options should be legally protected in buyer-seller

14. See, for example, Aetna Bldg. Maintenance Co. v. West, 39 Cal.2d 198, 206 (Cal. 1952); Rigging Intern. Maint Co. v. Gwin, 128 Cal.App.3d 594, 611-612 (Cal. Ct. App. 1982); Simmons Hardware Co. v. Waibel, 47 N.W. 814 (S.D. 1891).

15. Carpetmaster of Latham, Ltd., v. Dupont Flooring Sys., Inc., 12 F.Supp.2d 257, 261-262 (N.D.N.Y. 1998).

16. See McDonnell Douglas Corp. v. NASA, 180 F.3d 303 (D.C. Cir. 1999); Gulf \& Western Industries, Inc. v. United States of America, 615 F.2d 527 (D.D.C. 1979) (denying requests under 5 U.S.C. $\S 552$ (b)(4)).

17. Alabama Power Company v. Federal Power Commission, 511 F.2d 383, 391 note 13 (D.C. Cir. 1974) (upholding a rulemaking by the predecessor of today's FERC which eliminates information asymmetries). The rulemaking exists, in modified form, up to the present day, see 16 U.S.C. $\S 824 d, \S 824$ e, 18 C.F.R. $\S 141.61$.

18. American Sumatra T. Corp. v. Securities and Exch. Comm'n, 110 F.2d 117 (D.C. Cir. 1940) (upholding a decision by the SEC which denied a request for confidential treatment of the plaintiff's filings which could be used by the plaintiff's customers to calculate the plaintiff's profit margin).

19. See only $\S 220$ (b) Delaware General Corporation Law. The same analysis applies to the right of inspection under common law.

20. See, for example, the American Airlines, Inc. v. FareChase, Inc. controversy, which was ultimately settled out of court. For more information, see http://cyberlaw.stanford.edu/taxonomy/ term/4 and Southwest Airlines Co. v. FareChase, Inc., 318 F.Supp.2d 324 (D.S.C. 2004). 
relationships is not confined to trade-secret law. Although most decisions are very fact dependent, in general, courts seem somewhat reluctant to grant legal protection in such cases. Generally, this is in line with the model presented in this article. In many cases, firms either do not need incentives in order to create the information they attempt to protect or do not make any attempts to conceal this information. In such cases, our model argues against legal protection. When, however, our model argues for legal protection, the law is flexible enough to grant it.

\section{Conclusion}

Information is valuable in vertical buyer-seller relations. We have analyzed whether it should be protected by trade-secret laws. The answer is generally yes: Introducing a fine for the violation of a trade secret is welfare increasing. What is less clear is the optimal size of the fine. We have found ambiguous effects. Protecting the information with high fines is undesirable if the adverse selection dimension of the problem is important, that is, if there is significant danger that inefficient trade would occur. If, however, the informed party can undertake relation-specific investments to increase the gains from trade, asymmetry of information and therefore trade-secret protection is desirable as it protects such investment incentives. In addition, fines deter wasteful rent-seeking activities by the uninformed party.

Since in legal practice the relative size of the various effects is difficult to measure, we investigated private damages and conditional trade-secret protection as institutions which are less informationally demanding, and which are both part of the current legal practice. We find that both institutions tend toward the socially beneficial direction of limiting the application of trade-secret protection to cases in which its benefits are large. However, identifying the size of private damages in vertical relationships is usually difficult, and therefore conditional trade-secret protection with a fixed fine might be a superior solution.

Current legal practice combines both instruments. Although our analysis points out that this can be beneficial, it also highlights important drawbacks of such a combination. Imagine that buyers can expect to receive punitive damages in excess of their actually accrued damages. In this case, a combination of punitive damages and conditional trade-secret protection is dangerous. It sets incentives for buyers to invest in concealing just to be eligible for the damages. With punitive damages in particular, this can result in significant welfare losses (due to wasteful concealing and due to the increasing probability of inefficient trade).

One "compromise" to solve this is to decouple the payment to the plaintiff from the damages accrued by the defendant. If courts can vary the size of the punishment depending on the ex post observed size of actually accrued damages in terms of the lost information rent, only a fraction of this amount should be passed to the plaintiff. This provides additional arguments for "split awards" in addition to the arguments in favor of such arrangements that result from the 
attempt to reduce litigation costs. ${ }^{21}$ Combining this strand of literature with our view on trade-secret protection opens interesting new research questions.

\section{Appendix A: Proof of Proposition 1}

From equation (2), we get by implicit differentiation that the optimal effort choice $e^{*}$ is strictly increasing in $\gamma_{\mathrm{S}}$ :

$\frac{\partial e^{*}}{\partial \gamma_{\mathrm{S}}}=-\frac{-\frac{\partial \alpha}{\partial \gamma_{\mathrm{S}}} \frac{\partial b}{\partial e}}{(1-\alpha) \frac{\partial^{2} b}{\partial e^{2}}}<0$.

Rewriting equation (7) yields

$$
\int_{\widehat{c}}^{\bar{c}} c \mathrm{~d} F(c)+\int_{\widehat{c}}^{\bar{c}} b\left(e^{*}\right)-(b(0)-c)-p^{m} \mathrm{~d} F(c)=\frac{\frac{\partial \phi}{\partial \gamma_{\mathrm{S}}}+\frac{\partial \beta}{\partial \gamma_{\mathrm{S}}} D}{\frac{\partial \alpha}{\partial \gamma_{\mathrm{S}}}} .
$$

Call the term on the left-hand side $V$ and the one on the right-hand side $R$. Implicit differentiation yields that

$$
\frac{\partial \gamma_{\mathrm{S}}}{\partial e^{*}}=-\frac{\frac{\partial V}{\partial e}}{-\frac{\partial R}{\partial \gamma_{\mathrm{S}}}} \text {. }
$$

The denominator is positive since we evaluate the function at the profit maximum. For $V$, we need to take into account how $\widehat{c}$ changes with $e$ :

$\frac{\partial V}{\partial e}=-\frac{\partial \widehat{c}}{\partial e}\left(b\left(e^{*}\right)-b(0)\right)+(1-F(\widehat{c})) \frac{\partial b}{\partial e}$,

which is positive since $\frac{\partial \widehat{c}}{\partial e}=\frac{\partial b(e)}{\partial e}\left(\frac{\partial p^{m}}{\partial b(e)}-1\right)<1$ (varying $b(e)$ shifts the demand function; since the demand is downward sloping, the monopoly price changes by less than the shift). Therefore, $\frac{\partial \gamma_{\mathrm{S}}}{\partial e^{*}}>0$ and the best response functions intersect exactly once in the $\left(e, \gamma_{S}\right)$-space (our assumptions on $\phi$ and $\beta$ guarantee strictly positive quantities in equilibrium).

\section{References}

Bagnoli, M., and T. Bergstrom. 2005. "Log-Concave Probability and Its Applications," 26 Economic Theory 445-69.

Bone, R.G. 1998. "A New Look at Trade Secret Law: Doctrine in Search of Justification," 86 California Law Review 241-313.

Choi, A., and C.W. Sanchirico. 2004. "Should Plaintiffs Win What Defendants Lose? Litigation Stakes, Litigation Effort, and the Benefits of Decoupling," 33 Journal of Legal Studies 323-54. Friedman, D.D., W.M. Landes, and R.A. Posner. 1991. "Some Economics of Trade Secret Law," 5 Journal of Economic Perspectives 61-72.

21. See the original argument by Polinsky and Che (1991) in favor of decoupling payment to the plaintiff from damages accrued by the defendant in order to save litigation costs in case of a fixed probability of success in trial. Alternative results are derived for the case in which the size of litigation costs affects the probability of trial success (see, e.g., Choi and Sanchirico 2004, or Landeo and Nikitin 2006). 
Genscape, Inc. 2004. "Apparatus and Method for the Measurement and Monitoring of Electrical Power Generation and Transmission." US Patent 6,771,058.

2. 2006. "Apparatus and Method for Monitoring Power and Current Flow." US Patent $7,088,090$.

2007. "Method and Apparatus for Monitoring Fluid Flow." US Patent 7,274,996.

Grosskopf, O., and B. Medina. 2008. "A Revised Economic Theory of Disclosure Duties and Break-Up Fees in Contract Law," 13 Stanford Journal of Law, Business and Finance 148-87.

Hefermehl, W., H. Köhler, and J. Bornkamm. 2008. Wettbewerbsrecht. 26th ed. Munich: C.H.Beck.

Hermalin, B.E., and M.L. Katz. 2006. "Privacy, Property Rights and Efficiency: The Economics of Privacy as Secrecy," 4 Quantitative Marketing and Economics 209-39.

Hirshleifer, J. 1971. "The Private and Social Value of Information and the Reward to Inventive Activity," 61 American Economic Review 561-74.

Kitch, E.W. 1980. "The Law and Economics of Rights in Valuable Information," 9 Journal of Legal Studies 683-723.

Kronman, A.T. 1978. "Mistake, Disclosure, Information, and the Law of Contracts," 7 Journal of Legal Studies 1-34.

Landeo, C.M., and M. Nikitin. 2006. "Split-Award Tort Reform, Firm's Level of Care, and Litigation Outcomes," 162 Journal of Institutional and Theoretical Economics 571-600.

Levin, J. 2001. "Information and the Market for Lemons," 32 RAND Journal of Economics $657-66$.

Milgrim, R. 2008. Trade Secrets. Albany, NY: Matthew Bender.

Myerson, R., and M. Satterthwaite. 1983. "Efficient Mechanism for Bilateral Trading," 29 Journal of Economic Theory 265-81.

Polinsky, A.M., and Y.-K. Che. 1991. "Decoupling Liability: Optimal Incentives for Care and Litigation," 22 RAND Journal of Economics 562-70.

Posner, R.A. 1981. "The Economics of Privacy," 71 American Economic Review 405-9.

Shavell, S. 1994. "Acquisition and Disclosure of Information Prior to Sale," 25 RAND Journal of Economics 20-36.

Stigler, G.J. 1980. "An Introduction to Privacy in Economics and Politics," 9 Journal of Legal Studies 623-44. 